\title{
New treatment options in antidepressant therapy
} George Alevizopoulos*

\author{
Address: Athens University Medical School, Aeginition Hospital, Athens Greece
}

* Corresponding author

\author{
from International Society on Brain and Behaviour: 2nd International Congress on Brain and Behaviour \\ Thessaloniki, Greece. 17-20 November 2005 \\ Published: 28 February 2006 \\ Annals of General Psychiatry 2006, 5(SuppI I):S50 doi:10.1 I86/1744-859X-5-SI-S50
}

The goals of antidepressant treatment are to induce remission and prevent relapse or recurrence. While response is the standard criterion applied to comparisons of antidepressant drugs indicating an improvement from baseline, the more stringent criterion of remission is more relevant to clinical practice because it indicates that the patient is symptom-free. Studies with many antidepressants demonstrate response rates up to $60 \%$ but remission rates less than $30 \%$.

Co-occurring somatic symptoms are suggested as risk factors predispose to low remission rates. $50 \%$ of depressed patients report pain while many different types of pain occur more frequently in people with depression than in non-depressed control populations. Pain and depression may share common pathways and may both respond to treatment with certain antidepressants. Selection of optimal antidepressant therapy should consider drugs that have the greatest potential to induce remission. It is important to evaluate antidepressants in terms of its efficacy in relation to that of reference agents such as the tricyclics, SSRI's and MAOI's. 